\title{
ALgORITHM FOR CHOOSING FACTORY PlanNing MeThods AND TOOLS
}

\author{
HENNERSDORF, S. \& DOMBROWSKI, U.
}

Abstract: Factory planning is an important subtask of corporate planning. To face actual and future challenges enterprises are forced to start continuous factory planning activities. Especially for small and medium sized enterprises (SME) a practice-oriented proceeding to tackle the new challenges is still missing. The factory planning algorithm developed by the IFU ensures coordinated planning processes as well as the specific selection of appropriate factory planning methods and tools in a systematic and enterprise specific way. Therefore, this paper describes a systematic way to select factory planning methods and tools.

Key words: production, planning, industrial engineering, factory
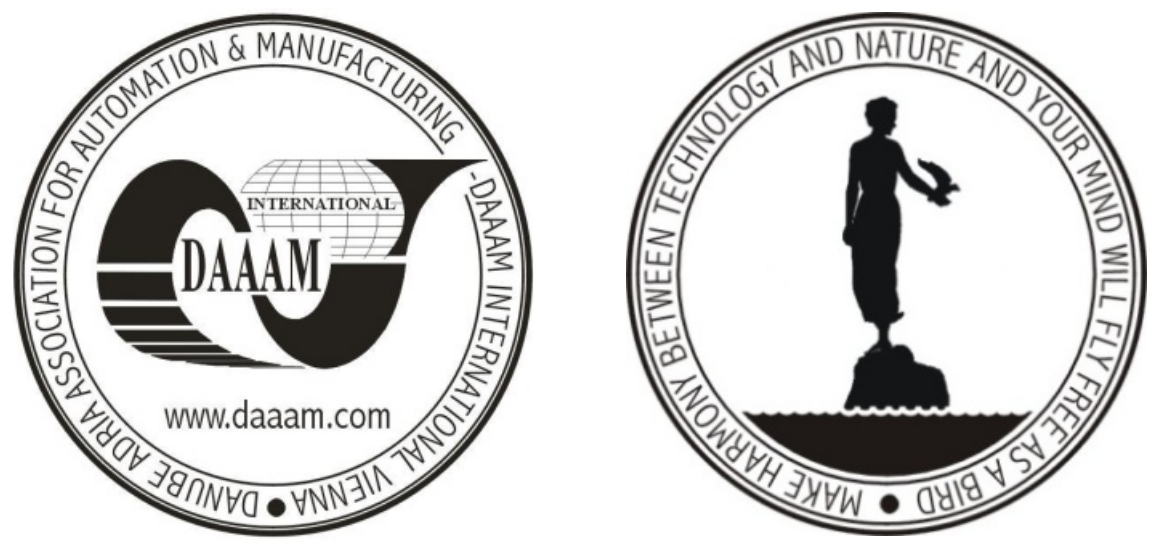

Authors' data: Dipl.-Wirtsch.-Ing. Hennersdorf, S[ibylle]; Univ.-Prof. Dr.-Ing. Dombrowski, U[we], Technical University Carolo-Wilhelmina of Braunschweig, Institute for Production Management and Operations Research, Langer Kamp 19, 38106 Braunschweig, Germany, u.dombrowski@tu-bs.de, s.hennersdorf@tu-bs.de

This Publication has to be referred as: Hennersdorf, S[ibylle] \& Dombrowski, U[we] (2009). Algorithm for Choosing Factory Planning Methods and Tools, Chapter 06 in DAAAM International Scientific Book 2009, pp. 045-052, B. Katalinic (Ed.), Published by DAAAM International, ISBN 978-3-901509-69-8, ISSN 1726-9687, Vienna, Austria

DOI: 10.2507/daaam.scibook.2009.06 